\title{
Understanding Interoperability in Collaborative Network Management: the Case of Metro High School
}

\author{
Aleksey Kolpakov ${ }^{1}$, Robert Agranoff ${ }^{2}$ and Michael McGuire ${ }^{2}$ \\ 1. Department of Political Science, University of Nevada, Reno 89557, USA \\ 2. School of Public and Environmental Affairs, Indiana University, Bloomington 47405, USA
}

\begin{abstract}
The increasing importance of interoperability (IOp)—reciprocal communication and accommodation among government organizations and NGOs to develop interactive policy and programming-has become an integral part of networked organizations, now utilized beyond IOps's emergency management origins in public administration. Using a mixed methods approach, this paper empirically examines IOp in a networked STEM (science, technology, engineering and mathematics) secondary school that includes 16 school districts and their public agency and NGO partners, particularly in its planning and operational phases. It also identifies the growing use of IOp in a number of non-emergency management settings and raises the prospects for utilizing this type of interorganizational management in the public arena.
\end{abstract}

Key words: Interoperability, collaboration, public management networks.

\section{Introduction}

If management in the public sphere is to be advanced beyond the usual calls for increased interagency/interlevel "negotiation and adjustment", "mutual accommodation", or "working agreements", research must become more serious regarding how multiagency plans and operations unfold. These networked undertakings have been identified under the rubric of interoperability (IOp). As a core aspect of collaborative management, IOp has been defined as reciprocal communication and accommodation to reach interactive policy and programming [1]. For an example related to emergency management, Wise (2006) identifies how communities network with the federal, state, and local governments while working with NGOs to avoid the more devastating effects of disasters like floods, hurricanes, and forest fires by attempting to make their policies and procedures work interactively toward similar or common aims [2]. IOp has once again become visible with the serious

Corresponding author: Aleksey Kolpakov, assistant professor, Ph.D., research fields: public management, collaborative management and governance.
AMTRAC derailment in mid-2015 that led to eight deaths and multiple injuries, which could have been prevented by installing automated safety speed mechanisms using IOp principles. To understand how such management operations interface would appear to be part of the core of what the current era of managers need to know regarding managing across boundaries, not only in the emergency but in integrating many public operations.

This article takes an empirical look at IOp through a deep look inside a networked structure, Metro High School in Columbus, Ohio, which is an accelerated science, technology, engineering, and math (STEM) entity uniquely operated by numerous public agencies and NGOs, particularly 16 area school districts, The Ohio State University, Knowledge Works (part of a national coalition of experimental schools), and a leading research NGO, Battelle Corporation. Metro's continuously evolving managerial structure blends network policy and management, educational programming, and operational procedures. It presents a real world look at IOp outside of the emergency management that includes both planning and operations. Our combined qualitative and quantitative 
study methodology allows for identification of key IOp properties known from the intraorganizational literature: mutuality or reciprocity, degree centrality, betweenness centrality, operational roles, structural holes, and brokerage roles. This analysis will add to the general understanding of this seemingly complex operation that is now recognized as IOp.

While little is known about IOp in detail, if one breaks down the process it indeed appears protracted. In the business field interoperations are at the heart of “execution” where planning and operations are brought together by tightening links. For a group of organizations that must work together, IOp is a focused internal-external effort to enhance collaborated organizational learning [3]. In this regard, the U.S. Government Accountability Office published a report on the National Incident Fire Command's Wildland Fire learning process that involves five federal agencies along with multiple state governments and state-based NGOs, varying in involvement depending on each forest area [4]. Broken down, the policy involves ten broad overlapping steps: bringing together disparate resources and agencies; documenting of agency/organization sequences and procedures; developing a command and control structure; establishing an agreed-upon management strategy; finding a resource redeployment sequence; setting an agency "donated" staffing sequence; agreeing and setting common standards, policies, and procedures, including equipment deployment; incident response policies and procedures; forming and operating a "council" or networked organized structure; and negotiating and setting interorganizational policies and procedures. To the uninvolved it is likely that only the final step regarding policies and procedures would appear to be the essence of IOp. In practice it is a "big deal," so to speak. In a sense, IOp is a form of an operating community of learning, as people share a common repeatable methodology, focusing on use of similar terminology and techniques based on pooled experiences [5].

Interoperable management can be further distinguished from its close administrative relations: (1) interoperational consultation, which entails effort to seek out information or advice across agency lines about a singular practice; (2) interoperable transactions, such as over a grant or contract of a bi-agency nature; and (3) interoperational coordination, whereby two or more agencies regularly share information or client referrals but do not operate internally on an interactive basis [6]. IOp in contrast refers to regularized programming involving two or more entities for which operating policies and processes have been articulated and are executed interactively to considerable degrees.

The article proceeds as follows. First, we provide other working examples of IOp in practice in other arenas beyond our STEM education study. Second, we attempt to tease out the key elements of IOp from the literature. Third, we introduce Metro High School as a networked entity and summarize previous work on network management sequencing [7]. Fourth, the Metro study methodology is explained, which combines qualitative grounded theory and quantitative research based on a participant survey. Also, the IOp processes that form the focus of this study are presented. Fifth, the findings on IOp are documented and explained. Sixth, the implications of the IOp findings and suggestions for subsequent research steps are offered. The article concludes with a call for additional deeper examination into network management processes, given emerging public policy challenges from other program areas such as welfare-to-work, habilitation of the intellectually disabled, and implementation of the Affordable Care Act.

\section{Increasing Importance of IOp as Network Management}

As a key GAO report for homeland security concluded, the principal challenge in developing 
effective IOp communications is not technical but cultural and organizational. The three principal challenges for the U.S. Department of Homeland Security were and are:

(1) clearly identifying and defining the problem; (2) establishing national interoperability performance goals and standards that balance nationwide standards with the flexibility to address differences in state, regional, and local needs and conditions; and (3) defining the roles of federal, state, and local governments and other entities in addressing interoperable needs [8].

These are quintessentially issues of an interorganizational nature, calling for some extensive form of collaborative management.

What are the core elements of IOp? Its technical elements were previously highlighted from one case as the ten steps involved in NFC were distilled. Its cultural and organizational elements have been analyzed by Wise and Jenkins. Wise (2006, 313) concludes that homeland security IOp, facing complexity and high rates of change, needs a networked rather than a hierarchical model, "a challenge of interagency and intergovernmental affairs" [2]. He concludes that IOp efforts need to engage in "adaptive models" that include defining and articulating common outcomes, establishing reinforcing or joint strategies, identifying needs and leveraging resources, agreeing on agency roles and responsibilities, establishing compatible policies and procedures, developing cross-agency monitoring mechanisms, reinforcing agency and individual accountability, and involving an array of intergovernmental and NGO actors [2]. Wise concludes that this type of adaptive management involves "putting into place a formal framework that facilitates interpersonal interaction” across agencies and levels” (315). Following Wise's conclusions, Jenkins (2006, 321) points to the difficulties in ongoing organizations to compel that such behaviour changes can happen. He calls for structures and processes "that provide incentives and rewards for collaboration, consultation, and support for implementing key goals" [1]. In the same respect, Jenkins calls for clear problem identification, establishing IOp goals, and defining roles of government and other involved entities.

The use of IOp extends well beyond emergency management and disaster response recovery. The Denver area Metropolitan Planning Organization (MPO) has put a great deal of emphasis on planning for land use, growth control, and coordination of local use of space, balanced with multimodal transport using a consensus-based IOp approach [9]. Also, Medicaid-funded programs with few exceptions are normally operated by the states through a set of contracts and purchase of services ranging from externalized/contracted case management to a series of medically related direct services (e.g. dental, vision, physical therapy) subcontracts that buttress the work of primary private health care agencies and practitioners, who must be connected around the client [10]. Since the mid-1990s, CALFED, a federal state partnership, has evolved into an operating multisectoral effort at water quality that emphasizes science-based standards. It has attempted the difficult task of integrating the Sacramento and San Joaquin river basin, while looking at operating problems and attempting to deal with large water suppliers [11]. Later in the article, four other nonemergency disaster management IOp examples will be highlighted, including U.S. Coast Guard's Deepwater program, the Medicaid Home and Community-based Waiver for persons with intellectual/developmental disabilities, the Affordable Care Act of 2010, and the Rotterdam Netherlands Water Square recovery project.

IOp involves both process and technical aspects of systems that need to be integrated by making components of systems work together [12-14]. Indeed, Glazer (2012, 119) concludes, “an operation must first be organized... and is fueled by effective decision-making and effective decision-making is driven by data" [15]. This, in regard to operations, "is made possible by a long chain of enablers, working 
backwards to define the work system" [15]. In regard to IOp it involves many more managerial actions across boundaries than the mere designing of organizations. Also, working multiple organizational structures in separate (analytical or real-time) networks/networking as distinct entities is clearly in order.

Along with the functions of IOp systems it is important to identify the decision-making, structural, and information components. For example, with regard to the Incident Management (ICS) fire control system, four key functions are core. They go beyond that of command and interactive decision-making:

- Operations to manage all tactical activities

- Planning, gathering, and evaluating current and forecasting information

- Logistics to provide ongoing support for network participants

- Financing administration to track money and time on handling situations [16, 17]

These functions are differentiated in both large, complex systems and with single agency commands. They are generally highly diffused among network actors in IOp processing. In either case these systems are characterized by "a set of processes and procedures through which information about the system is assembled and analyzed, predictions are made about how things will evolve, options are developed and decided on, and plans are formulated. Regular briefings and cycles of planning are the hallmark of ICS in action" [16]. Moreover, many of the studies of emergency management networks underscore the importance of employing mechanisms that engender cultures of trust, assembling and developing timely information and communications technology, and working toward mutual goal adjustment among interorganizational actors who bring disparate goals to the table [18].

\section{Metro Setting/Preliminary Work}

This research for examining IOp processes emanates from our study of Metro High School, Columbus, Ohio, a STEM network entity of public and private agencies. Metro's major learning partners include the Educational Council (16 Franklin county school districts), The Ohio State University (OSU), national and state Coalitions for Essential Schools (Knowledge Works in Ohio), and Battelle Corporation, a research entity. As Figure 1 indicates, there is much more to this operation, including important learning sites where students have internships, projects, field placements, and classes; the PAST Foundation that organizes research, field learning, and dissemination of STEM learning to the 16 school districts; contractual arrangements with OSU for student counseling; OSU leadership and educational resources; and such other community resources as industry/educator curricula taskforces and the use of OSU Library as the Metro Library.

Metro is "governed" by the Educational Council (EC) upon the advice of the Metropolitan Partnership Group (MPG), a network steering group, administered by the Metro School administration and the Educational Council staff. The school admits about 100 students for each class, by interview and lottery, apportioned by school population among the 16 districts, and operates on an accelerated basis and by subject mastery.

Students must master the 18 subject-related credits required for Ohio high school graduation, normally in their first two years, after which they attend classes at OSU for credit. In addition to the network that undergirds the operation of the school, a community of students, teachers, and parents are involved in many aspects of the school experience.

The Metro is an excellent case for studying interoperability in public management networks. On one hand, Metro is both a formal, networked structure that has a clear structure and defined goals as well as clear procedures that were jointly developed. On another hand, Metro can also be defined as a collection of informal relationships among the individuals that transcend organizational, governmental, and sectoral boundaries. By design, Metro unites numerous network 


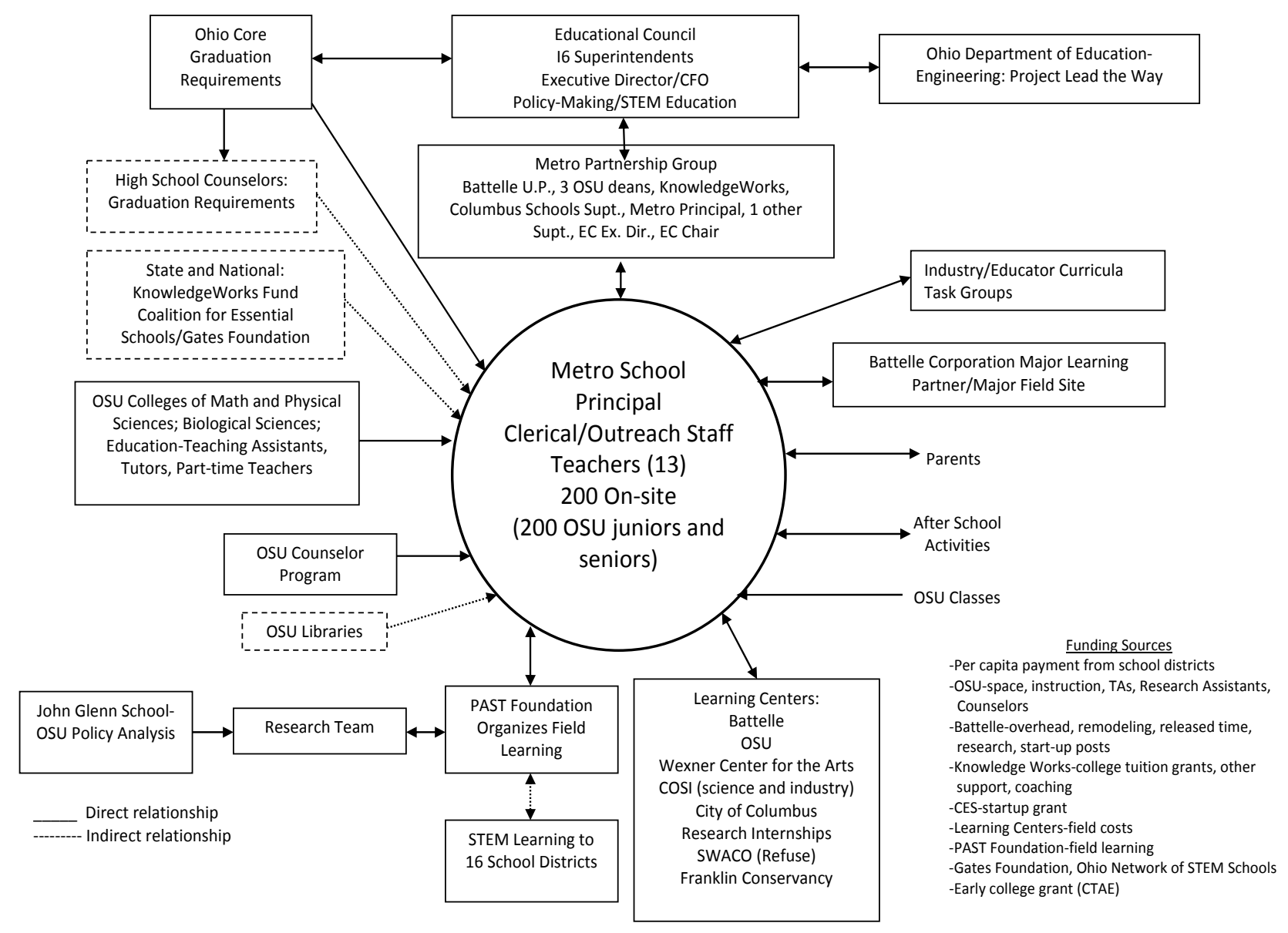

Fig. 1 The Metro Network.

actors with multiple connections engaged in the various collaborative activities, which requires constant negotiation and communication.

\section{Methodology}

The study reported in this article utilizes a longitudinal case study design combining quantitative/network data and qualitative data, where different levels of network analysis provide a global and thick picture of interoperability processes. The use of a case study for this kind of research emanates from the established tradition of studying collaborative processes in public management networks by Agranoff and McGuire [6, 7, 12, 19].

The qualitative data were gathered through semi-structured interviews with 28 key representatives of 17 organizations. They were identified by the snowball sampling technique, based on initial discussions with the staff of Metro High School, network founders and leaders as a part of the research sequence of qualitative-data collection, and analysis adopted by Agranoff for researching public management networks [19]. These 28 representatives were asked about their involvement in the project at the different stages and history of Metro from its beginning. In addition, the authors asked specific questions related to the various processes that lead to the formation and management of the Metro network including decision making, planning, negotiation, development of rules, internal and external communication, accountability, making decisions, planning activities, disseminating information, and mobilizing participants to action. The complete description of all steps in this research sequence can be found in Table 1. 
Table 1 Research sequence for qualitative data collection and analysis.

\begin{tabular}{ll}
\hline$\#$ & Research activity \\
\hline 1 & Design by major conceptual and research question development \\
2 & Preliminary case orientation and scanning the terrain by gathering documents and other relevant information \\
3 & Preliminary selection of initial prospective discussants \\
4 & Formatting and outlining of the discussant interactions \\
5 & Preparation of the guide for focused discussions in the field \\
6 & Interviews/guided discussions with initial discussants \\
7 & Identification of other relevant discussants \\
8 & Completing all guided discussions \\
9 & Recording of post-interview impressions and transcript develoment \\
10 & Organizing information into categories of data-primary, secondary and theoretical coding \\
11 & Development of conceptual findings
\end{tabular}

Analysis of the discussant-generated data was conducted with the transcripts developed from the completed discussion guides (protocols for semi-structured interviews) for each discussant, which included information from answers to more than 400 total question responses. The researchers reviewed the interview data, coding responses in relation to the research questions and organizing the responses according to the research design outline. During this process, researchers considered and compared explanations seeking patterns, while establishing conclusions that were most congruent with the data. This process was a rigorous and consistent mode of examining and comparing information. As a means to answer a few selected research questions and further analyze the discussant data, the qualitative research software package NVivoTM was used as an analytical and data sorting tool. It should be noted that the NVivoTM analysis did not replace the coding process used by the researchers, but rather pointed them to quotes, comments, and other types of notes that enabled them to develop and/or verify conclusions that emerged from the interpretive coding.

The quantitative data were gathered by means of 2-page questionnaires, where each respondent was asked to identify up to 16 individuals and identify the types of formal relations that are essential to the network development and the concept of interoperability. The formal relations include information exchange, finance exchange, joint planning, negotiation and operations. The informal relations were measured by personal knowledge, social relations (degree of friendship and kinship) and trust. Both formal and informal relations were measured using a 6-point Likert scale ranging from Never (0) to Daily (5) to detect the frequency of particular relation with other network members.

In addition, we constructed the directed network at the stage of planning using the results of coding the interviews with 28 key respondents. This network represents the working relations at the stage of planning and encompasses various activities such as initial meetings, curriculum development, learning program development, finding and allocating resources. Similarly, the network of working relations during the implementation stages was constructed on the responses to the questions regarding the Metro School involvement with others during the implementation. The results of the coding were verified by the Likert responses (0-never, 1-yearly, 2-quarterly, 3-monthly, 4-weekly, 5-daily) to the questions related to information provision and operations.

The original analysis of the quantitative and qualitative data include a qualitative grounded theory study of Metro's network developmental phase, which is supplemented by the basic analysis of a series of 
quantitative network descriptive data [7]. This data was based on 44 network operation related respondents who reported a total of 310 connections.

To understand the dynamics of key interoperable properties known from the intraorganizational literature, such as reciprocity, operational roles, structural holes, and brokerage rules, we have reconstructed the network relations at the planning stage based on coding the responses of 28 key representatives to the questions about Metro history, their personal involvement and their connections.

The commonly used measures of public management networks such as centrality, betweenness and reciprocity [20] were computed to understand the structural implications of interoperability, using UCINET [21]. This analysis looks at the more or less standard frequency and types of connections, measures of network centrality (in degree and betweenness), information exchange patterns, and network planning patterns, along with various reciprocal patterns.

Degree centrality is measured by the number of ties held by one particular node [20]. Since the present data relate to a directed network, degree centrality is measured by the outdegree and indegree centrality. The outdegree centrality is a measure of the number of ties coming out of a node or a network actor. The indegree centrality is a measure of the number of ties coming to a node or a network actor.

Reciprocity or mutuality relates to the number of symmetric ties among the network actors and can be found by dividing the number of symmetric ties by the number of potentially symmetric ties [22].

Betweenness centrality measures the degree to which a network actor is directly connected to those nodes in the network that happen not to be connected directly to each other [20]. Betweenness measures the degree to which one particular node serves as a bridging point between different network actors. Betweenness centrality is measured by the actor betweenness index, which is found by dividing the number of geodesics linking actors $i$ and $j$ that pass through node $\mathrm{k}$ by the number of all geodesics linking actors $\mathrm{i}$ and $\mathrm{j}$.

\section{Findings}

In general, we were able to discern three important patterns for Metro that are relevant to the concept of interoperability. First, the school's line contact operatives, the Metro teachers, were only marginally connected to the network's interactions and operations. Second, the "planning network" is not inclusive with only a few key participants and does not include the Learning Partners, particularly those sponsors of students and others arrayed about Figure 1, such as the learning centers and others. This can be confirmed by the visual inspection of the operational relations in Figure 2 where 13 isolates (nodes of a network that are not connected to other nodes or network players) are clearly present. Third, a clearly identified core network leadership group emerged during the planning stage including the Metro Principal, a small core of district superintendents who were activists on the 16 district Educational Council, the Dean of the OSU College of Biological Sciences, the Battelle project manager and the Battelle Vice President for Outreach. In this respect, it was clear that while a great deal of attention has been paid to the technical core of a network and its operations, a clear interagency leadership core that has the ability to mobilize resources as well as knowledge, may well be key, as they serve to mobilize support and establish legitimacy. These persons appear essential in networks [23].

Combining our qualitative and quantitative data suggests that Metro Network is managed by the principle of "soft guidance". Finding the multiple focal nodes is an accurate description of the way decisions are made and actions are taken [24]. Such guidance is the network equivalent to the more familiar direct supervision in hierarchical organizations. The most central participants-the Metro principal and the CEO of the Educational Council—apparently are significant for information flow and planning, but they do not 


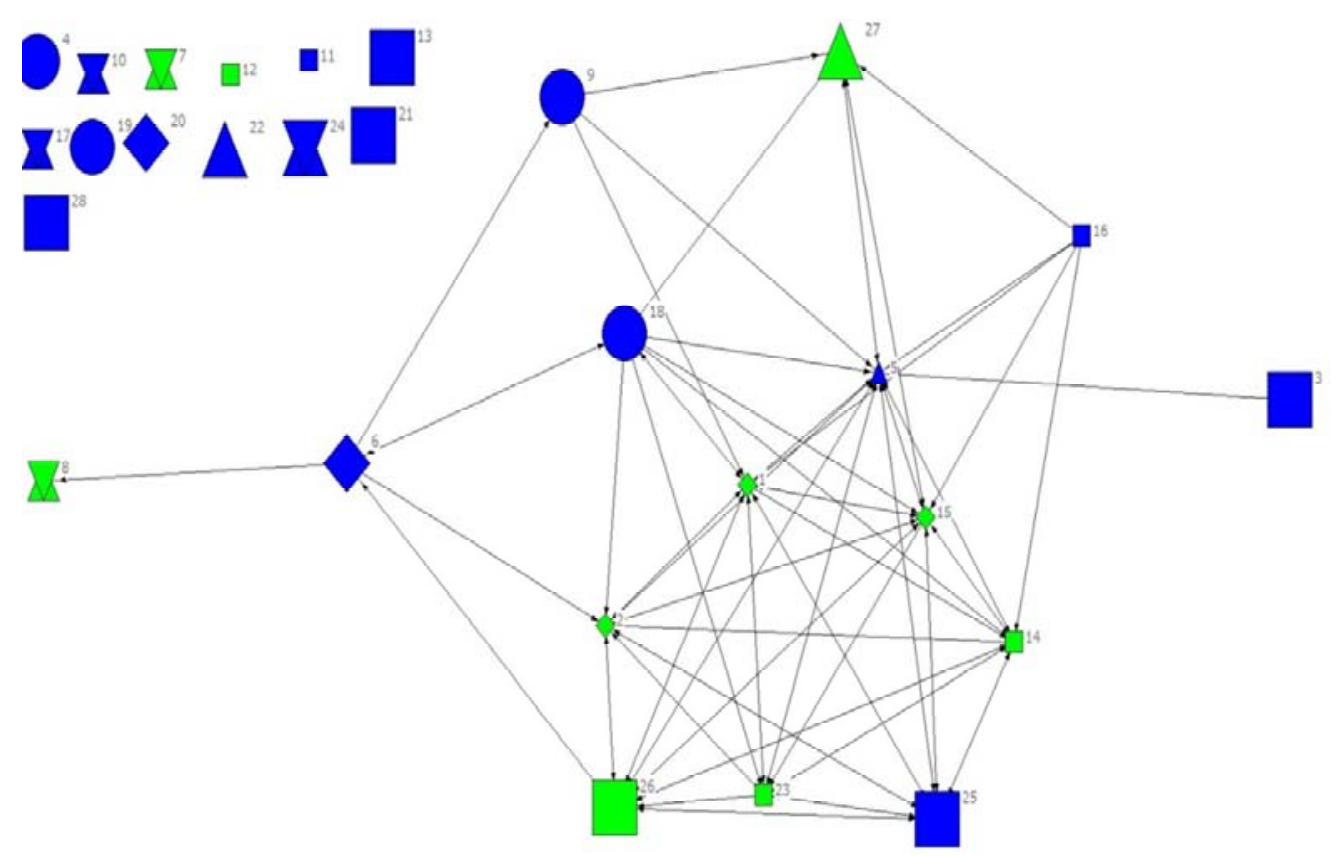

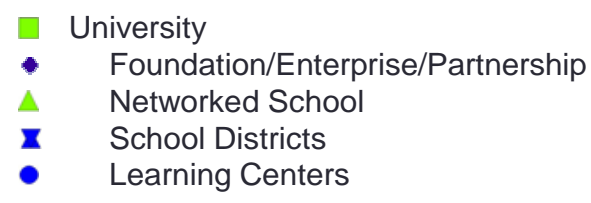

Fig. 2 Metro network at the planning stage.

dominate the operations of the network. The school principal is indeed the center of the Metro universe, but there is substantial evidence from previous network research that suggests a focal "hub" or hubs can be critical to network success [25]. Although the classical approach views networks as flat, self-organizing, completely interdependent entities, we have found that, in practice, a network center that appears to emerge operationally is not uncommon. Case studies of community mental health networks, for example, demonstrate that the effectiveness of the networks was based in part on the extent to which the network was coordinated centrally through a core agency [23]. At Metro, the principal appears to be that hub, although other nodes have been, and remain, indispensable to Metro's operation.

The visual inspection of the operations network in Figures 2 and 3 suggests that the Metro network of
Notes:

Gender: male - green; female - blue

Size of the node: bigger nodes indicate presence of previous interorganizational network experience operational relations became more centralized as the project progressed from the stage of formation to the stage of implementation. In the planning stage, the Metro network of operational relations was more or less decentralized with many central players involved in the formation of Metro School such as CEOs of The Ohio State University, Battelle Memorial Institute, Knowledge Works and the Educational Council. The "implementation network" is characterized by fewer centers with many connections. The most critical players with multiple connections at the stage of implementation include the principal of Metro High School, the CEO of the Educational Council, a manager of the PAST Foundation, a top Battelle manager, and a Battelle project manager in residence, which constitutes the network leadership core. The peripheral group included the members of the Educational Council, employees of OSU, and learning partners providing field experiences. 


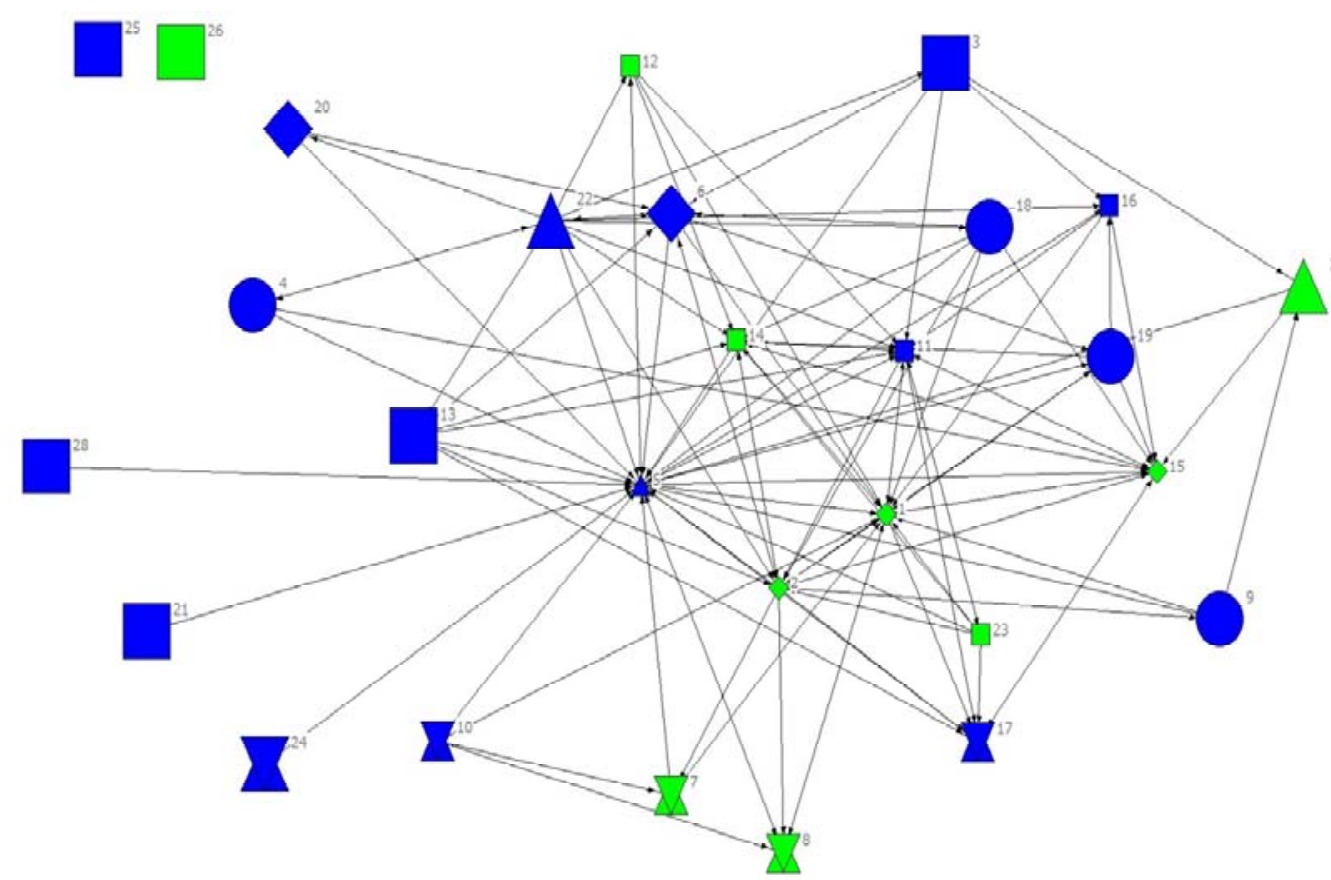

University

Foundation/Enterprise/Partnership

Networked School

School Districts

- Learning Centers
Note:

Gender: male - green; female - blue

Size of the node: bigger nodes indicate the presence of previous interorganizational network experience

Fig. 3 Metro network at the implementation stage.

Table 2 SNA measures of interoperability at different stages of development: Metro Network.

\begin{tabular}{lll}
\hline & Planning stage & Implementation stage \\
\hline Centralization (outdegree) & $20.17 \%$ & $29.49 \%$ \\
Centralization (indegree) & $35.53 \%$ & $79.42 \%$ \\
Density & $10.19 \%$ & $16.01 \%$ \\
Reciprocity & $50.98 \%$ & $26.04 \%$ \\
Betweenness centrality & $3.92 \%$ & $22.66 \%$ \\
\hline
\end{tabular}

Reciprocity is another structural feature of IOp clearly observed in the Metro network. The close look at the working relations of networks in the planning and implementation stages points at more "reciprocation" in the planning stage (Table 2). About 51 percent of the working relations were reciprocated at the planning stage with four key members enjoying highest reciprocation. They include former president of OSU (100 percent of ties reciprocated), CEO of Battelle (75 percent of ties reciprocated), director of Knowledge Works (70 percent of ties reciprocated), the CEO of the Educational Council (60 percent of ties reciprocated). On the other hand, the implementation network is characterized by a decreased level of reciprocation since only 26 percent of working relations were reciprocated and many network members had lost reciprocal relations with others. Nevertheless, four key network leaders had the highest levels of reciprocity: the director of Knowledge Works (about 55 percent of ties reciprocated), one school superintendent (55 percent of ties reciprocated), the CEO of the Educational Council (44 percent of ties 
reciprocated) and the CEO of Past Foundation (43 percent of ties reciprocated). Most of them represent institutions responsible for developing policies for the interagency interactions. For example, Educational Council deals with the issues of disciplining Metro High School students that come from the different school districts.

Betweenness centrality is another structural characteristic that helps to understand and measure IOp in public management and nonprofit organizations. Betweenness centrality serves as a proxy for measuring the control of the information flow in the public management network. Table 2 suggests a considerable increase in betweenness centrality, from 4 percent in the planning stage to 23 percent in the implementation stage, as the Metro school developed. Higher scores in betweenness centrality can be interpreted as higher dependency on other organizations and better flow of information and resources in the network [26, 27].

More detailed analysis of individual scores of betweenness centrality of working relations in the planning and implementation network reveals the conceptual linkage of betweenness centrality and IOp. The highest scores of betweenness in the planning stage belong to the CEO of Battelle, a network leader who brought in different players during the planning stage (normalized betweenness score $=4.44$ ), the Battelle project manager, a liaison between Metro and Battelle (normalized betweenness score $=3.7$ ), and the Metro High School principal (normalized betweenness score $=3.64)$. All three of these Metro network members played a pivotal role in the formation of Metro School by bringing the right players with the right resources to ensure the successful development of the network. In addition, all of them were involved in the processes of negotiations and facilitation of various meetings including the stakeholder and general public meetings (townhall meetings). For example, the Battelle project manager organized meetings with different network actors and worked with Metro Partnership Group and COSI, whereas the Metro school principal involved all partners, including student parents.

The implementation stage is characterized by the increase of betweenness scores and change of the leader responsible for negotiations with various stakeholders. The highest betweennness score this time belongs to the vice president of Battelle responsible for mobilizing and maintaining corporate engagements between Battelle and its stakeholders (normalized betweenness score $=26.07$ ). Another network player who served a role of a liaison between Metro and Battelle (normalized betweenness score $=20.35$ ) is the responsible Battelle project manager. Finally, the Metro school principal still has held an important position in terms of negotiations and rule-making.

\section{The Challenges Involving IOp}

Defining separate components of interoperability can be seen at first as a daunting task, but the findings of exploratory social network analysis suggests distinguishable elements of this complex and governance related concept. First, separation of governance or planning core and operational core is essential for the proper placed system of interoperability. The effectively placed governance structures such a Metro Partnership Group and the Educational Council allow planning, gathering, and evaluating current and forecasting information. The operational core becomes more developed during the implementation stage and is responsible for managing all tactical operations. This is structurally translated into few centers in the network responsible for inter-agency programming.

Second, agreement on the roles and responsibilities of participating agencies is another element of interoperability, which can be measured by reciprocity. The increased level of reciprocity at the initial stages of development can be understood in light of IOp in its execution phase. In the beginning of the collaboration, network members need to agree on roles and responsibilities and establish compatible policies and 
procedures. This requires a great deal of two way communication and interaction to set rules, norms and values for the effective future functioning of the network [28]. Finally, control of information and increase in negotiations is another procedural aspect of IOp that can be measured by the betwenness centrality. High level of betwenness indicates the constant patterns of negotiation with representatives of different agencies to achieve optimal use of resources.

IOp by many other labels will become increasingly important as organizational paradigms shift to interorganizational domains. While the need for IOp has been with us for some time, it is clearly an extension of post-modern dedifferentiation across agency lines [29]. As more networked operations like Metro emerge, newer entities that are organized (but not organizations in the classical sense) will have to be "managed" through IOp processes.

In this respect, Metro is an organized undertaking that has unusual public agency standing. Metro was initially made possible by the dedicated energies of key community leaders, particularly the former president of OSU and the CEO of Battelle, whose support and resource commitments moved others to support the STEM plus small school concept. Several identifiable levels now combine to constitute the Metro's network: the Educational Council, the Metro Partnership Group, Knowledge Works, the Metro principal, and Battelle. As the school continues operations, layers of teachers, learning site representatives, and support personnel from OSU have also become network participants. Metro's operations extend well beyond the walls and staff of the school, involving the active learning and support activities of many partner resources and the learning centers throughout the metropolitan area.

\section{IOP and Other Nonemergency Management Settings}

This kind of activity will increasingly call for IOp as program management crosses boundaries. For example, the Affordable Care Act (ACA) has brought on protracted interorganizational processing challenges among 16 state-run insurance exchanges, and 34 (19 federally-run, of which seven are federal-state, seven are federally-facilitated marketplaces, plus Utah's small business marketplace) with federal involvement. An estimated 55 NGO contractors and subcontractors are collaborating, who all claim their part is working fine but it is their interaction with other segments that has given rise to the problem [30].

It is no wonder that an early study of ACA reports other IOp challenges as: (1) eligibility transitions between Medicaid, Children's Health Insurance Program (CHIP), tax subsidized insurance through healthcare exchanges, and unsubsidized private employer-sponsored health insurance; implementing compliance-based standardized policies over fifty different health care systems; (3) the slow pace of introducing program changes into the Medicaid Management Information System; (4) achieving consistency with state-oriented HIPAA (Health Insurance Portability and Accountability Act of 1996) practices; (5) adaptations to ever-changing and last-minute rule changes across federal-state programs like Medicaid and state-regulated insurance programs; and (6) applying the lessons from the Massachusetts experience, including standards and regulations that are interactively derived from all stakeholders, including consumers and consumer advocates, significant marketing and outreach to inform the public regarding available coverage options and the range of subsidies, and an open and accessible enrollment process [30]. To say the least, it is a massive, seemingly overwhelming IOp challenge that goes beyond software application and exchange planning by state insurance leaders.

A similar type of IOp dynamic has been existent since the 1980s with regard to the Medicaid Home and Community Based (HCBS) Medicaid Waiver, which allows states to finance disabled clients at risk of being placed out of institutional settings. HCBS has financed an array of community services in all states-personal 
assistance, public accommodations, employment, technology access, post-school training-that are coupled with housing and income support in search of integrated client-based services [13]. The federal-state program allows for the necessary crosswalks between services and programs focused on maintaining disabled persons out of institutions and large facilities [10, 13, 32]. These crosswalks require massive IOp undertakings at the client, interagency, program, and state agency levels that have been well documented for some time [14].

Similar IOp challenges are also considerable with regard to Welfare-to-Work programs under the 1996 welfare reform. They link state public assistance programs with career centers, state vocational rehabilitation agencies, employer associations, industry groups, internship sites, individual employers, education and training institutions, Workforce Investment Boards, local economic development agencies, and other entities. Under the Personal Responsibility and Work Opportunity Act of 1996, federal welfare programs were converted to capped state block grants, temporary assistance to needy families (TANF), that not only limited benefits but gave states flexibility in adapting to work and training programs and transferring program funds across welfare titles [33]. Massive IOp challenges in bringing employment and training together with public assistance have ensued as a result and persist [34].

The U.S. Coast Guard's Deepwater Program involves multiple mission efforts designing service's operations that present many challenges in the interaction of the multiple missions of safety (marine, search and rescue, navigation security, drug interdiction, migrant interaction, defense readiness, other law enforcement) and stewardship (marine environment protection, living marine resources). It was organized to acquire a system of interoperable assets whose seamless communication and coordination would make the whole system greater than the sum of the parts [35]. This interrelated system was led by a government/private sector programs in a state of command, control, communications, computers and intelligence, surveillance, and reconnaissance system, known as C4ISR.

The program involves a series of complex products since its specifications, performance standards, costs and mission impacts were difficult to pre-establish. In addition, the Coast Guard was unable to predetermine cost estimates particularly due to the lack of exact system arrangements and asset design specifications. It became a great systems design and execution challenge because of the complexity of this government orchestrated program/product.

For the U.S. government Deepwater Program became what is known as "system of systems" contracting involving the lead systems in integration or each major component. It refers to a general system comprised of several discrete systems that contribute to the overall goal where components remain relatively discrete in orientation. With regard to Deepwater, the various components-boats, helicopters and airplanes_-are capable of acting independently or are part of a larger system. As the authors of IOp program analysis conclude [35]:

Concerns about the SoS strategy have less to do with the approach and more to do with who is tasked with designing and producing the macro-system, namely the LSI. On the one hand, LSIs are simply general contractors, linking together system elements-the boats, airplanes, and helicopters-and ensuring that they are able to coordinate to form the system. In this way, governments buy from LSIs all the time. When the military acquires a fighter jet, for example, it does not typically order wings, landing gear, a cockpit, and other component parts from separate suppliers that arrive in boxes marked "some assembly required." Instead, the military turns to a vendor that delivers a fully functional fighter jet. On the other hand, LSIs may move beyond simply performing product or system integration functions and take on a task and function that is inherently governmental, that is, the function" 
(Brown, Potoski, and Van Slyke. 2008, 19).

LSI contractors are then primarily responsible for complex products that involve output based results that are difficult to specify in advance. As a result, specifications and outcome are the jointly analyzed, negotiated and adjusted at multiple stages in the program, by Integrated Project Teams of multiple stakeholders who are convened to collaborate and share information to determine project-related product specifications and requirements while in the midst of production.

For the Coast Guard, the massive array of assets allows for tapping into the systems design and engineering capacities inside and outside of government into an IOp network system. It has built in systems that allow for parts of the process to move forward as design changes and prices are agreed upon. This IOp process allows for "legally anchored" flexibility as well as the Coast Guard's use of a number of private sector contractor management tools, for example EVM, where dual costs are compared with performance. This case of IOp provides a means for government to be interactive in conducting an extremely complex multistage processes while maintaining these core concerns of contracting, maintaining public interests values, respect for and working within institutions, laws and organizational arrangement, and enjoying the services and their markets that are to activate stakeholder values [36].

The concept of IOp wholeheartedly embraces the realities of multiple stakeholders with different expectations when it comes to the establishment of multiple connections at the different levels. The Rotterdam, Netherlands Water square project is reflective of many public construction projects that involve many public agencies, private construction firm projects, researchers and citizen groups. It involved water collection from many small sources into a large discharge facility. After a protracted siting process, a pilot project around local schools and many public citizen meetings were held. Next, negotiation over involved local schools and resolution of potential soil problems were approached. As plans moved into operations people from the architectural and construction firms worked with city employees, on issues including from maintenance, recreation, education, safety, soil and those involved had to navigate their way through by working interactively with other stakeholders, both private and public, within this context of complexity and face challenges in an adaptive way instead of relying on pre-existing plans. Indeed it involved the participation of the multiple stakeholders in both the design and operation processes. The process brought out the importance of multi-stakeholder connectivity at as the project moved through its various stages [37].

\section{Conclusions}

Further research in IOp is clearly needed. Overall, IOp involves organizational representatives working across domains, using "soft guidance" to move toward mutual reciprocation as core or specialized organization based information is reciprocally exchanged. In the Metro study, line contact operations fell out of the IOp network as operational interactions unfolded, whereas a planning network was clearly distinguished from a core leadership group. What has emerged from the Metro experience is the transformation of network learning across various organizational domains. This was empirically confirmed in Bruns study of scientific research coordination [38]. In her work, IOp type coordination occurred through the combination and arrangement of three types of practices: 1 ) expert practice that yields special contributions, 2) coordination practice that arranges contribution across domain boundaries, and 3) collaborative practice that modifies expert practices. As a result, disparate scientific contributions become compatible and "inter workable". It would appear that IOp would have to break down these processes even further for example, with regard to such major policy challenges as planning and execution would involve 
many actors representing different public and nonpublic organizations coming from multiple disciplines, missions, and knowledge bases. Therefore, more research studies are needed to show the application of the concepts of IOp in different policy areas where public, nonprofit and private organizations join their forces to alleviate wicked policy problems such as poverty, low preparedness of high school students for colleges, environmental pollution, growing crime rates, provision of social services to vulnerable populations and low economic development.

IOp is clearly entering the intersectoral domain lexicon and practice in public management. For example, the Recovery Act of 2009 included the Health Information and Technology for Economic and Clinical Health (HITECH) provisions that included financial incentives through Medicare and Medicaid to install interactive electronic health records (EHRs). This IOp initiative is designed to operate in three phases. First, involves aggregation of disparate medical and health records. Second, starting in 2014, was the beginning of the record interchange of information for enforcing interoperability enhancement standards and improving the exchange across systems [39]. Such IOp improvements will be critical for reducing duplicate testing and facilitating research studies in order to determine what interventions work in given situations. A third, extremely ambitious phase of HITECH will focus on the development of technology to improve patient outcomes using the previously developed integrated systems. Thus, the HITECH Act is one ambitious attempt at moving EHR into interoperability [39].

The challenges of ACA, HCBS and Workforce investment are but a few of the examples where public programs require more than effective and efficient operating of single programs. As Paul Light $(2010,184)$ concludes “... achievement requires significant collaboration across the aisles and institutions” [34]. Numerous parties not only embrace complex and potentially vexing ideas, but also engage in the type of persistence and a mix of incremental adjustments punctuated by the larger decisions. IOp is symbolic of this type of process, as public administration tries to make the parts move in similar directions.

\section{Acknowledgments}

Authors wishes to acknowledge the support from the Battelle Center for Mathematics and Science and Past Foundation in gathering data for this project.

\section{References}

[1] Jenkins, W. O. 2006. “Collaboration over Adaptation: The Case for Interoperable Communications in Homeland Security.” Public Administration Review 66 (3): 319-21.

[2] Wise, C. R 2006. "Organizing for Homeland Security after Katrina: Is Adaptive Management what's Missing?” Public Administration Review 66 (3): 302-18.

[3] McFarland, K. R. 2008. The Break through Company, Crown Business, New York.

[4] U.S. Government Accountability Office (GAO), 2006. Results-Oriented Government: Practices That Can Help Enhance and Sustain Collaboration among Federal Agencies, Government Printing Office, GAO-06-15, Washington, D.C.

[5] Harpst, G. 2008. Six Disciplines Execution Revolution, Six Disciplines Publishing, Findlay, Ohio.

[6] Agranoff, R., and McGuire, M. 2003. Collaborative Public Management: New Strategies for Local Governments, Georgetown University Press, Washington, D.C.

[7] McGuire, M., and Agranoff, R. 2014. Network Management Behaviors: Closing the Theoretical Gap, in Keast, R., Mandell, M., and Agranoff, R. (eds.), Network Theory in the Public Sector, Routledge, New York.

[8] Department of Homeland Security, 2005. A Comprehensive and Sustained Management Approach Needed to Achieve Management Integration, Government Printing Office, GAO-05-139, Washington, D.C.

[9] Margerum, R. D. 2005. "Collaborative Growth Management in Metropolitan Denver: Fig Leaf or Valiant Effort?” Land Use Policy 22: 373-86.

[10] Thompson, F. J. 2012. Medicaid Policies: Federalism, Policy Durability and Health Reform, Georgetown University Press Washington, D.C.

[11] Kallis, G., Kiparsky, M., and Norgaard, R. 2010. "Collaborative Governance and Adaptive Management: Lessons from California's CALFED Water Program.” Environmental Science and Policy 12 (6): 631-43.

[12] Agranoff, R. 1991. "Human Services Integration: Past and 
Present Challenges in Public Administration.” Public Administration Review 51 (6): 426-36.

[13] Agranoff, R. 2013. "The Transformation of Public Sector Intellectual/Developmental Disabilities Programming.” Public Administration Review 73 (Special Issue on Health Care): 5127-38.

[14] Agranoff, R., and Pattakos, A. N. 1979. Dimensions of Services Integration, Project SHARE, Rockville, MD.

[15] Glazer, H. 2012. High Performance Operations, Pearson Education, Upper Saddle River, NJ.

[16] Howitt, A. M., and Leonard, H. B. 2009. Structuring Crisis Response in Howitt, A. M., and Leonard, H. B. (eds.), Managing Crises: Responses to Large-Scale Emergencies, Congressional Quarterly Press, Washington, D.C.

[17] Varley, P. 2009. The 9/11 Pentagon Emergency (A), in Howitt, A. M., and Leonard, H. B. (eds.), Managing Crises: Responses to Large-Scale Emergencies Congressional Quarterly Press, Washington, D.C.

[18] Kapucu, N., Garayev, V., and Wang, X. H. 2013. "Sustaining Networks in Emergency Management." Public Performance and Management Review 37 (1): 104-33.

[19] Agranoff, R. 2007. Managing Within Networks: Adding Value to Public Organizations, Georgetown University Press, Washington, D.C.

[20] Wasserman, S., and Faust, K. 1994. Social Network Analysis: Methods and Applications. Cambridge University Press, New York, NY.

[21] Borgatti, S. P., Everett, M. G., and Freeman, L. C. 2002. Ucinet for Windows: Software for Social Network Analysis, Analytic Technologies, Harvard, MA.

[22] Wasserman, S., and Pattison, P. 1996. "Logit Models and Logistic Regressions for Social Networks: I.” An Introduction to Markov Graphs and P. Psychometrika 61 (3): 401-25.

[23] Provan, K. G., and Milward, H. B. 1995. “A Preliminary Theory of Interorganizational Network Effectiveness: A Comparative Study of Four Community Mental Health Systems.” Administrative Science Quarterly: 1-33.

[24] Windhoff-Hentier, A. 1992. The Internationalization of Domestic Policy: A Motor of Decentralization, European Consortium for Political Research Joint Session, Limerick, Ireland.

[25] Meier, K. J., and O'Toole, L. J. 2003. "Public Management and Educational Performance: The Impact of Managerial Networking." Public Administration Review 63 (6): 689-99.

[26] Kapucu, N., Augustin, M.-A., and Garayev, V. 2009.
"Interstate Partnerships in Emergency Management: Emergency Management Assistance Compact in Response to Catastrophic Disasters.” Public Administration Review 69 (2): 297-313.

[27] Ansell, C., Reckhow, S., and Kelly, A. 2009. "How to Reform a Reform Coalition: Outreach, Agenda Expansion, and Brokerage in Urban School Reform.” Policy Studies Journal 37: 717-43.

[28] Rank, O. N., Robins, G. L., and Pattison, P. E. 2010. "Structural Logic of Intraorganizational Networks." Organization Science 21 (3): 745-64.

[29] Clegg, S. R. 1990. Modern Organizations: Organization Studies in the Postmodern World, Sage, London.

[30] Dionne, E. J. 2013. ACA Works in States That Are Doing What Law Envisioned. Hoosier Times, Oct. 27, E6.

[31] Doonan, M. 2013. American Federalism in Practice: The Formulation and Implementation of Contemporary Health Policy, Brookings, Washington, D.C.

[32] Thompson, F. J., and Burke, C. 2009. "Federalism by Waiver: MEDICAID and the Transformation of Long-term Care.” Publius: The Journal of Federalism 39 (1): 22-46.

[33] Conlan, T. J., Posner, P. L., and Beam, D. R. 2014. Pathways of Power: The Dynamics of National Policy Making, Georgetown University Press, Washington, D.C.

[34] Light, P, C. 2010. From Endeavor to Achievement and Back Again: Government's Greatest Hits Imperil. In Steven Conn's, To Promote the General Welfare: The Case for Big Government, Oxford University Press, New York.

[35] Brown, T. L., Potoski, M., and Van Slyke, D. M. 2008. The Challenge of Contracting for Large Projects: A Case Study of the Coast Guard's Deepwater Program, IBM Center for the Business of Government, Washington, D.C.

[36] Brown, T. L., Potoski, M., and Van Slyke, D. M. 2006. "Managing Public Service Contracts: Aligning Values, Institutions, and Markets.” Public Administration Review 66 (3): 323-31.

[37] Bressers, N. 2014. The Impact of Collaboration on Innovative Projects: A Study of Dutch Water Management. In Public Innovation through Collaboration and Design. Eds. Ansell, C. and Torfing, J., Routledge, London.

[38] Bruns, H. C. 2013. "Working Alone Together: Coordination in Collaborations across Domains of Expertise.” Academy of Management Journal 56 (1): 62-83.

[39] Emanuel, E. T. 2014. Reinventing America's Healthcare, Public Affairs, New York. 